\title{
Is Awareness of Chronic Kidney Disease Associated with Evidence-Based Guideline-Concordant Outcomes?
}

\author{
Delphine S. Tuot ${ }^{a, b}$ Laura C. Plantinga ${ }^{d}$ Chi-yuan Hsu ${ }^{a, b}$ Neil R. Powe ${ }^{b, c}$ \\ ${ }^{a}$ Division of Nephrology, and ${ }^{b}$ Department of Medicine, University of California, and ${ }^{\mathrm{c} C e n t e r ~ f o r ~ V u l n e r a b l e ~}$ \\ Populations, San Francisco General Hospital, San Francisco, Calif., and d Department of Epidemiology, Emory \\ University, Atlanta, Ga., USA
}

\section{Key Words}

Chronic kidney disease - Awareness - National Health And

Nutrition Examination Survey (NHANES) • Guidelines

\begin{abstract}
Background: Awareness of chronic kidney disease (CKD) is low. Efforts are underway to increase recognition of CKD among patients, assuming that such an increase will lead to better outcomes through greater adherence to proven therapies. Few studies have tested this assumption. Methods: CKD awareness, defined by a 'yes' answer to 'Have you ever been told by a healthcare provider you have weak or failing kidneys?', was assessed among 2,404 adults with CKD stages 1-4, who participated in the 2003-2008 National Health and Nutrition Examination Surveys. Odds of blood pressure (BP) control, self-reported use of angiotensin-converting enzyme inhibitors (ACEI) or angiotensin receptor blockers (ARB), and glycemic control, were determined among those aware vs. unaware of their CKD. Results: Optimal BP control, ACEI/ARB use and glycemic control were low in the US adult population with CKD, although there was a recent increase in attainment of guideline-concordant BP control. Odds of BP control and ACEI/ARB use were not different among individuals aware of their CKD compared to those unaware (ad-
\end{abstract}

justed odds ratio (AOR) 0.91; 95\% Cl 0.52-1.58 and AOR 0.75; 0.44-1.30, respectively). CKD awareness among diabetic participants was not associated with glycemic control (AOR 0.41; 95\% Cl 0.14-1.18). Conclusion: Awareness of CKD is not associated with more optimal BP control, ACEI/ARB use or glycemic control. Future efforts in this area should further explore the measurement of CKD awareness and behaviors associated with CKD awareness.

Copyright $\odot 2012$ S. Karger AG, Basel

\section{Introduction}

Chronic kidney disease (CKD) is common [1] and associated with excessive mortality and morbidity. Better CKD management - through evidence-based medical therapies - improves outcomes [2]. It is generally accepted that awareness of CKD by providers and patients is critical for implementation and adherence to those therapies.

Blood pressure (BP) control, use of an angiotensinconverting enzyme inhibitor (ACEI) or angiotensin receptor blocker (ARB), and glycemic control are three evidence-based CKD practice guidelines known to slow progression of CKD to end-stage renal disease (ESRD)

\section{KARGER}

Fax +41613061234 E-Mail karger@karger.ch www.karger.com

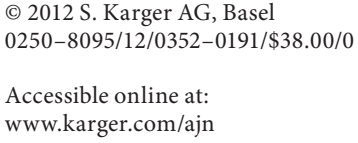

Delphine S. Tuot

1001 Potrero Avenue

Bldg 100, Room 342

Box 1341, San Francisco, CA 94110 (USA)

Tel. +1 415206 3784,E-Mail Delphine.tuot@ucsf.edu 
and to reduce cardiovascular-related complications [2]. National efforts to increase recognition of CKD among providers and patients [3] have been based partly on the premise that these efforts will lead to wider adoption of these therapies and, consequently, better health outcomes in patients with CKD.

Recent cohort studies have provided conflicting evidence regarding the association of primary care provider awareness of CKD with improved overall quality of CKD care, including greater prescription of ACEI/ARB and improved BP control $[4,5]$. Patient awareness of $\mathrm{CKD}$, arguably a determinant of medication adherence and BP control, was not examined in either study and may provide one explanation for the contradictory results. While individual awareness of CKD is integrally related to provider awareness, the two entities are separate. The influence of patient awareness of CKD on outcomes concordant with CKD practice guidelines is therefore important to understand and remains a gap in the literature.

Our primary objective was to test the hypothesis that individual awareness of CKD was associated with improved BP control, ACEI/ARB use, and glycemic control in a nationally representative sample of US adults with CKD with recent contact with the healthcare system. Because previous studies have demonstrated low levels of guideline-concordant CKD care in the United States [6, 7], we also hypothesized that prevalence of these outcomes would increase over time.

\section{Methods}

\section{Study Design}

The National Health And Nutrition Examination Survey (NHANES) is conducted by the National Center for Health Statistics to examine trends in disease prevalence in cross-sectional representative samples of noninstitutionalized US civilian residents [8]. We examined data from the 2003-2008 NHANES, after the National Kidney Foundation Disease Outcomes Quality Initiative (KDOQI) was introduced in 2002. All participants gave informed consent. The protocol was approved by an institutional review board.

\section{Study Population}

The total number of adult nonpregnant 2003-2008 NHANES study participants with CKD stages $1-4$ was 2,705. Individuals with an estimated glomerular filtration rate (eGFR) $<15 \mathrm{ml} /$ $\mathrm{min} / 1.73 \mathrm{~m}^{2}$ were excluded from the outset, since guideline-concordant care would differ in this population. Our main study population also excluded individuals who did not self-report awareness or unawareness of CKD $(n=13)$ and did not report a routine site for health care or having seen a health care provider within the previous year $(n=288)$. This restriction allowed the study population (final $n=2,404$ ) to represent a group of individuals receiving regular medical care, increasing the likelihood that awareness would be associated with guideline-concordant care.

\section{Definitions}

The predictor variable was awareness of CKD, defined by a 'yes' response to the questionnaire item: 'Have you ever been told by a doctor or other health professional that you have weak or failing kidneys (excluding kidney stones, bladder infections, or incontinence)?' [9].

Outcomes included achievement of three evidence-based therapies known to help slow the rate of CKD decline: BP control, use of ACEI/ARB, and glycemic control (among individuals with $\mathrm{DM})$. BP was considered controlled if the average measurement of systolic or diastolic BP was $\leq 130$ or $\leq 80 \mathrm{~mm} \mathrm{Hg}$.[10] Glycemic control was defined by glycosylated hemoglobin $<7.0 \%$ [11] among patients with self-reported DM.

CKD was defined using single assessments of eGFR and urinary albumin:creatinine ratios, according to the KDOQI staging guidelines [2]. Estimated GFR was calculated according to the 4 -variable Modification of Diet in Renal Disease (MDRD) Study equation for calibrated serum creatinine level [12].

\section{Measurements}

CKD awareness (via questionnaire) and the number and type of anti-hypertensive medications (from prescription bottles provided by the participant) were obtained during NHANES interviews. $\mathrm{BP}$ was measured during the exam; the mean of all measurements (at least three) was used. Serum glycosylated hemoglobin was measured by high-performance liquid chromatography. Serum creatinine was measured by the modified kinetic method of Jaffe; levels were corrected for different analyzers [13, 14]. Urine albumin was measured using a solid-phase fluorescence immunoassay; urine creatinine was measured using the modified Jaffe kinetic method [14]. Self-reported sociodemographic variables and diagnoses were obtained during NHANES interviews.

\section{Statistical Methods}

Participant characteristics were compared by awareness and unawareness of CKD by $\chi^{2}$ and Wilcoxon rank-sum tests. Prevalences of outcomes concordant with evidence-based practice guidelines were estimated overall and by NHANES survey year. Variance of proportions was estimated with Taylor series linearization.

Multivariable logistic regression was used to estimate the independent association between CKD awareness and BP control, ACEI/ARB use, and glycemic control (among the subset with $\mathrm{DM})$. Because severity of renal dysfunction is associated with greater CKD awareness [1] and potentially with greater difficulty in achieving outcomes consistent with guideline-concordant care, we included propensity scores (in quintiles) for CKD severity, determined by characteristics that were shown or thought a priori to be associated with awareness and severity of CKD. Each model was further adjusted for potential confounders that remained significantly different among the aware and unaware study participants within each quintile of propensity score. Sensitivity analyses with different study populations were performed to assess robustness of the results: (i) restricted to indi- 
viduals with an eGFR $<60 \mathrm{ml} / \mathrm{min} / 1.73 \mathrm{~m}^{2}$; (ii) included all individuals with CKD irrespective of whether they had seen a healthcare provider in the previous year; and (iii) included individuals with CKD as defined by the CKD-EPI equation [15]. Additionally, given the current debate about target $\mathrm{BP}$ control in individuals with $\mathrm{CKD}$, a sensitivity analysis exploring a target $\mathrm{BP}<140$ or $<90 \mathrm{~mm} \mathrm{Hg}$ among individuals without albuminuria was performed.

To obtain nationally representative population estimates, all analyses were performed with appropriate weighting using the 'SVY' commands in Stata version 11 (StataCorp, College Station, Texas, USA).

\section{Results}

\section{Characteristics of the Study Population}

Only $7.4 \%$ of those with CKD and recent medical care self-reported awareness of CKD. Those who were aware were more likely to be non-Hispanic black and less likely to have completed a high school education. In addition to having more severe kidney dysfunction, individuals who were aware of their CKD were much more likely to have hypertension and self-reported diabetes (table 1).

\section{Outcomes Concordant with Evidence-Based \\ Guidelines}

Only 39\% achieved BP control and a mere $21 \%$ selfreported use of an ACEI/ARB. Among individuals with CKD and diabetes, 49\% achieved glycemic control. Among the individuals with an eGFR between 15 and 59 $\mathrm{ml} / \mathrm{min} / 1.73 \mathrm{~m}^{2}, 37 \%$ achieved BP control, $23 \%$ reported use of an ACEI/ARB, and, among those with diabetes, $57 \%$ achieved glycemic control.

There was a significant increase in achievement of BP control over time and a small but statistically significant decrease in ACEI/ARB use (fig. 1). Prevalence of glycemic control, however, did not change appreciably between 2003 and 2008. Awareness of CKD remained steady throughout this time period $\left(\mathrm{p}_{\text {linear trend }}=0.89\right.$ ).

\section{Relationship between Participant Awareness of CKD and Outcomes Concordant with Evidence-Based Guidelines}

Overall, awareness of CKD was not associated with greater odds of achieving of any of the three evidencebased CKD therapies examined in this study. Awareness of CKD was not associated with increased likelihood of BP control (table 2), an association that was not modified by CKD stage $\left(p_{\text {interaction }}=0.18\right.$ ) or presence of albuminuria $\left(p_{\text {interaction }}=0.19\right)$. Odds of ACEI/ARB use and glycemic control were not different among those aware vs.
Table 1. Characteristics of the US population with CKD, stratified by awareness of CKD (NHANES 2003-2008)

\begin{tabular}{|c|c|c|c|}
\hline & $\begin{array}{l}\text { Aware } \\
\text { (study } \\
\mathrm{n}=191 \text { ) }\end{array}$ & $\begin{array}{l}\text { Not aware } \\
\text { (study } \\
\mathrm{n}=2,213 \text { ) }\end{array}$ & $\begin{array}{l}\mathrm{p} \text { value } \\
\left(\chi^{2}\right)\end{array}$ \\
\hline \multicolumn{4}{|l|}{ Demographics, \% } \\
\hline Male gender & 47 & 40 & 0.12 \\
\hline Age, years & & & 0.06 \\
\hline $20-39$ & 10.2 & 13.2 & \\
\hline $40-59$ & 28.1 & 28.1 & \\
\hline $60-69$ & 26 & 16.2 & \\
\hline $70+$ & 35.7 & 42.5 & \\
\hline Race/ethnicity ${ }^{\mathrm{a}}$ & & & 0.02 \\
\hline Non-Hispanic white & 74.8 & 77 & \\
\hline Non-Hispanic black & 17.2 & 10 & \\
\hline Mexican-American & 2.6 & 4.6 & \\
\hline \multicolumn{4}{|l|}{ Greater than high school } \\
\hline education & 64.2 & 76.2 & 0.01 \\
\hline Has social support & 93.7 & 94.6 & 0.62 \\
\hline Currently married & 63.9 & 63.2 & 0.87 \\
\hline Non-English language & 2.2 & 4.4 & 0.02 \\
\hline Yearly family income, USD & & & 0.1 \\
\hline$<20,000$ & 35 & 24.2 & \\
\hline $20,000-44,999$ & 32.2 & 34.2 & \\
\hline $45,000-74,999$ & 19.1 & 21.4 & \\
\hline$>75,000$ & 13.6 & 20.3 & \\
\hline Has health insurance & 96 & 93.6 & 0.33 \\
\hline \multicolumn{4}{|l|}{ Co-morbid conditions, \% } \\
\hline Hypertension $^{\mathrm{b}}$ & 77.7 & 56.4 & 0.0001 \\
\hline Diabetes & 47.2 & 23.3 & $<0.0001$ \\
\hline Chronic Kidney Disease $^{c}$ & & & $<0.0001$ \\
\hline Stage 1 & 7.1 & 19.1 & \\
\hline Stage 2 & 17.6 & 27.6 & \\
\hline Stage $3 \mathrm{a}$ & 26 & 40.5 & \\
\hline Stage $3 b$ & 31 & 11.1 & \\
\hline Stage 4 & 18.4 & 1.6 & \\
\hline
\end{tabular}

Total $\mathrm{n}=2,404$ for all rows except education $(\mathrm{n}=2,399)$, social support $(n=2,196)$, marital status $(n=2,403)$, income $(n=2,236)$, insurance $(2,396)$, diabetes $(2,402)$.

a 'Other' not shown due to small sample size but are included in all analyses.

${ }^{\mathrm{b}}$ Hypertension defined by average BP or self-reported antihypertensive use.

${ }^{c}$ Staging determined by KDOQI guidelines. Albuminuria was considered present at urinary albumin-to-creatinine ratios of $>30$ $\mathrm{mg} / \mathrm{g}$.

unaware of their CKD, either overall or when stratified by eGFR or presence of albuminuria (table 2 ).

\section{Sensitivity Analyses}

Comparable results were noted when the study population was restricted to individuals with eGFR $<60 \mathrm{ml} /$ 
Table 2. Odds ratios (OR) of outcomes consistent with guideline-concordant care, if aware vs. unaware of chronic kidney disease

\begin{tabular}{|c|c|c|c|c|c|c|}
\hline & $\begin{array}{l}\text { Blood pressure } \\
\text { control } \\
\text { OR } \\
(95 \% \mathrm{CI})^{\mathrm{a}}\end{array}$ & $\begin{array}{l}\text { ACEI/ARB } \\
\text { use } \\
\text { OR } \\
(95 \% \mathrm{CI})^{\mathrm{a}}\end{array}$ & $\begin{array}{l}\text { Glycemic } \\
\text { control } \\
\text { OR } \\
(95 \% \mathrm{CI})^{\mathrm{a}}\end{array}$ & $\begin{array}{l}\text { Blood pressure } \\
\text { control } \\
\text { OR } \\
(95 \% \mathrm{CI})^{\mathrm{b}}\end{array}$ & $\begin{array}{l}\text { ACEI/ARB } \\
\text { use } \\
\text { OR } \\
(95 \% \mathrm{CI})^{\text {b }}\end{array}$ & $\begin{array}{l}\text { Glycemic } \\
\text { control } \\
\text { OR } \\
(95 \% \mathrm{CI})^{\mathrm{b}}\end{array}$ \\
\hline Overall population, unadjusted & $\begin{array}{l}0.84 \\
(0.50-1.38)\end{array}$ & $\begin{array}{l}1.26 \\
(0.77-2.07)\end{array}$ & $\begin{array}{l}0.67 \\
(0.29-1.57)\end{array}$ & $\begin{array}{l}0.90 \\
(0.55-1.49)\end{array}$ & $\begin{array}{l}1.18 \\
(0.71-1.97)\end{array}$ & $\begin{array}{l}0.70 \\
(0.30-1.62)\end{array}$ \\
\hline $\begin{array}{l}\text { Overall population, adjusted with propensity } \\
\text { score }^{\mathrm{c}}\end{array}$ & $\begin{array}{l}0.91 \\
(0.52-1.58)\end{array}$ & $\begin{array}{l}0.75 \\
(0.44-1.30)\end{array}$ & $\begin{array}{l}0.41 \\
(0.14-1.18)\end{array}$ & $\begin{array}{l}0.98 \\
(0.55-1.71)\end{array}$ & $\begin{array}{l}0.70 \\
(0.39-1.23)\end{array}$ & $\begin{array}{l}0.42 \\
(0.15-1.23)\end{array}$ \\
\hline $\begin{array}{l}\text { Among those with eGFR } 60-120 \mathrm{ml} / \mathrm{min} / 1.73 \mathrm{~m}^{2} \text {, } \\
\text { adjusted with propensity score }\end{array}$ & $\begin{array}{l}1.45 \\
(0.60-3.54)\end{array}$ & $\begin{array}{l}0.74 \\
(0.16-3.32)\end{array}$ & $\begin{array}{l}1.06 \\
(0.19-5.65)\end{array}$ & $\begin{array}{l}1.55 \\
(0.64-3.78)\end{array}$ & $\begin{array}{l}0.74 \\
(0.17-3.26)\end{array}$ & $\begin{array}{l}0.75 \\
(0.14-3.97)\end{array}$ \\
\hline $\begin{array}{l}\text { Among those with eGFR } 15-59 \mathrm{ml} / \mathrm{min} / 1.73 \mathrm{~m}^{2} \text {, } \\
\text { adjusted with propensity score }\end{array}$ & $\begin{array}{l}0.79 \\
(0.43-1.45)\end{array}$ & $\begin{array}{l}0.77 \\
(0.45-1.31)\end{array}$ & $\begin{array}{l}0.31 \\
(0.08-1.21)\end{array}$ & $\begin{array}{l}0.87 \\
(0.48-1.58)\end{array}$ & $\begin{array}{l}0.68 \\
(0.37-2.35)\end{array}$ & $\begin{array}{l}0.37 \\
(0.10-1.34)\end{array}$ \\
\hline $\begin{array}{l}\text { Among those with albuminuria, adjusted with } \\
\text { propensity score }\end{array}$ & $\begin{array}{l}1.37 \\
(0.71-2.63)\end{array}$ & $\begin{array}{l}0.89 \\
(0.44-1.82)\end{array}$ & $\begin{array}{l}0.47 \\
(0.15-1.43)\end{array}$ & $\begin{array}{l}1.34 \\
(0.70-2.60)\end{array}$ & $\begin{array}{l}0.87 \\
(0.42-1.78)\end{array}$ & $\begin{array}{l}0.45 \\
(0.16-1.3)\end{array}$ \\
\hline $\begin{array}{l}\text { Among those without albuminuria, adjusted } \\
\text { with propensity score }\end{array}$ & $\begin{array}{l}0.59 \\
(0.26-1.36)\end{array}$ & $\begin{array}{l}0.65 \\
(0.30-1.41)\end{array}$ & $\begin{array}{l}0.32 \\
(0.03-3.6)\end{array}$ & $\begin{array}{l}0.64 \\
(0.27-1.49)\end{array}$ & $\begin{array}{l}0.47 \\
(0.19-1.15)\end{array}$ & $\begin{array}{l}0.67 \\
(0.06-8.14)\end{array}$ \\
\hline
\end{tabular}

a eGFR was calculated with the MDRD Study equation.

${ }^{\mathrm{b}}$ eGFR was calculated using the CKD-epi equation.

${ }^{c}$ Propensity score determined by: age, gender, race/ethnicity, education, eGFR, albuminuria, presence of diabetes (except when modeling odds of glycemic control) and clinical markers of CKD [hyperkalemia, hyperphosphatemia, acidosis, elevated BUN, anemia and uncontrolled hypertension (except when modeling odds of BP control)]. In the model assessing odds of BP control, awareness of hypertension and number of anti-hypertensive medications were included in the propensity score. In the model assessing ACEI/ARB use, awareness of hypertension was included.

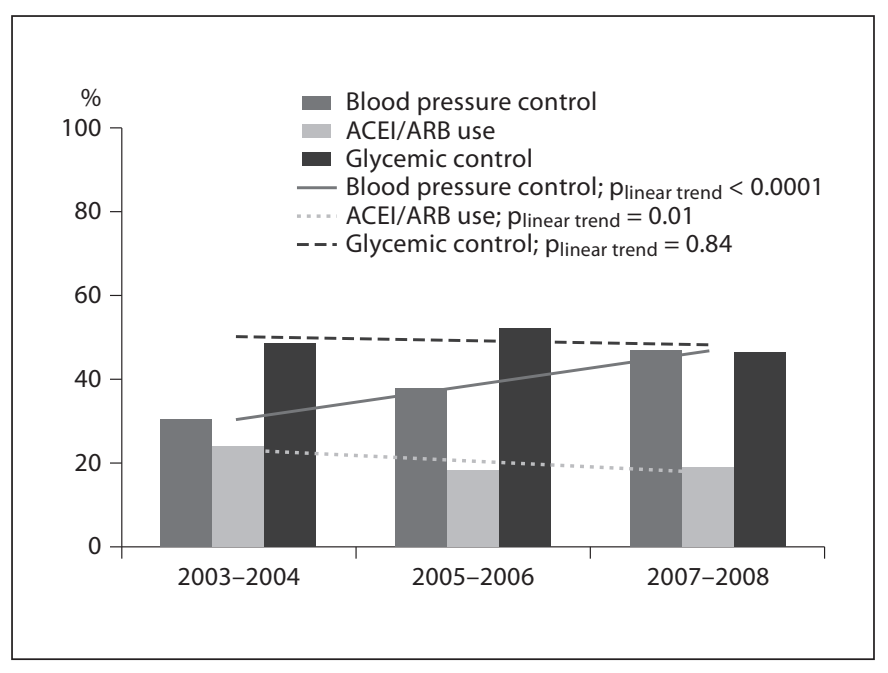

Fig. 1. US population prevalences of guideline-concordant CKD outcomes and temporal trend (NHANES 2003-2008). ed to include individuals with CKD who had had not seen a healthcare provider within the previous year or did not report a routine site for health care, awareness of CKD was not associated with greater achievement of guideline-concordant outcomes. Again, these associations were not modified by CKD stage or presence of albuminuria (data not shown). Analyses repeated with the CKD-EPI equation to define CKD also showed similar results (table 2).

When target $\mathrm{BP}$ was changed to $\leq 140$ or $\leq 90 \mathrm{~mm} \mathrm{Hg}$ among individuals without albuminuria, overall prevalence of BP control was higher in all years (40.2\% in 2003 $2004,48.3 \%$ in $2005-2006,60.4 \%$ in 2007-2008). Again, there was a statistically significant increase in achievement of BP control over those years ( $p_{\text {linear trend }}<0.001$ ). However, odds of BP control was not associated with awareness of CKD (AOR 0.84; 95\% CI 0.50-1.42).

\section{Discussion}

There are two main findings in this study. First, we found that - contrary to our hypothesis - individual awareness of CKD was not associated with better BP or glycemic control or more use of ACEI/ARB. Second, although we newly demonstrate an increase in attainment of $\mathrm{BP}$ control over time, we document overall low preva- 
lences of BP control, ACEI/ARB use and glycemic control in the US adult population with CKD using recent NHANES data. This adds to prior literature documenting limited achievement of guideline-concordant care among study populations $[7,16,17]$.

Individual awareness of chronic diseases, such as diabetes, hypertension, and congestive heart failure, has been associated with greater individual engagement in health care and adherence to medical therapies [18-22]. Educational interventions among patients nearing renal replacement therapy have also been associated with improvements in health outcomes, such as delays in initiation of dialysis and increased overall survival $[23,24]$. Thus, there is strong reason to believe that individual awareness of CKD would be associated with improved intermediate outcomes, such as achievement of guideline-concordant CKD care. Our findings that participant awareness of CKD was not associated with greater achievement of any of the three outcomes examined, were unexpected.

These findings, consistent with data from the Kidney Early Evaluation Program (KEEP) that have also demonstrated lack of association between CKD awareness and odds of BP control [7], may be explained in a variety of ways. Of course, it is possible that individual awareness of CKD does not actually influence achievement of guideline-concordant CKD care, contrary to what has been seen in other diseases. However, our data may also result from factors that obscure the true association between awareness and attainment of guideline-concordant care. Perhaps provider recognition of CKD and subsequent prescription of appropriate evidence-based CKD therapies play a far greater role than individual awareness of CKD in assuring good BP control, ACEI/ARB use and glycemic control. If individual awareness of CKD is not associated with provider prescription of CKD therapies, its influence on the outcomes studied would be minimal, consistent with our results. This could occur if health care providers are not fully aware of the CKD guidelines, do not believe the evidence behind the recommendation of such therapies, or believe that the prescription of such therapies is futile. It is also conceivable that providers become aware of, or focus on, their patients' CKD only at very advanced stages, at which point achievement of good BP and glycemic control and ACEI/ ARB therapy may be limited by side effects related to low eGFRs.

Additionally, our results may be due to poor discrimination among individuals who are aware vs. unaware of their CKD. Ascertainment of CKD awareness in the
NHANES survey is through the following question: 'Have you ever been told by a doctor or other health professional that you have weak or failing kidneys (excluding kidney stones, bladder infections, or incontinence)?' While this question may be very specific for CKD awareness - only $1.5 \%$ of individuals without CKD responded 'yes' to being aware of having CKD - it may lack sensitivity. Inclusion of individuals in the 'unaware' group, rather than the 'aware' group would result in misclassification and bias our study results towards the null.

The NHANES question is the only metric currently used to estimate population trends in CKD awareness. Our results raise concern that the question may have poor performance characteristics, i.e., it may be very insensitive, particularly among individuals with limited health literacy, who have lower objective knowledge about kidney disease [25]. To the best of our knowledge, the question used in NHANES has not been validated against a gold standard. Further, it lacks face validity. In an informal survey of practicing nephrologists, none volunteered that they use the terms 'weak or failing' kidneys to describe chronic kidney disease, except when patients are very close to needing dialysis (i.e. stage $5 \mathrm{CKD}$ ). While our study outcomes - achievement of guidelineconcordant CKD care - are imperfect benchmarks against which this question should be evaluated, we believe that they offer insight into the limitations of this question.

There are several limitations to this study. Causality cannot be inferred because of the cross-sectional nature of NHANES data. Also, reverse causality (e.g., difficultto-control BP leading to increased awareness of underlying CKD among providers and patients) cannot be ruled out. Further, the association between individual awareness of CKD and achievement of evidence-based medical therapies may be confounded by severity of CKD, as it is much more difficult to achieve BP control, maintain daily ACEI/ARB use, and achieve glycemic control in individuals with low eGFRs. While we used propensity scores to account for CKD severity, residual confounding may still be present. In addition, provider characteristics and details about provider-patient relationships, which likely affect guideline-concordant care, were not available. Also, we did not have data on persistently low renal function or albuminuria, which may have led to misclassification of CKD status.

In summary, prevalences of guideline-concordant CKD outcomes are low, though prevalence of BP control has recently increased. In addition, individual awareness of CKD does not appear to be associated with outcomes 
consistent with guideline concordant care. This suggests that CKD awareness may be important, but insufficient for achievement of optimal CKD care. Greater confidence in our metric to measure CKD awareness is necessary prior to fully embracing these results. Nevertheless, our findings challenge us to better understand the implications of CKD awareness in order to develop educational interventions aimed at improving health outcomes among individuals with CKD.

\section{Acknowledgements}

We thank the participants and staff of NHANES.

\section{Support/Disclosures}

DST was supported by the American Kidney Fund Clinical Scientist in Nephrology Fellowship and currently receives support from Award Number KL2RR024130 from the National Center for Research Resources. C.Y.H. is partially supported by K24DK92291 and N.R.P. is partially supported by grant K24DK02643, both from the National Institute of Diabetes and Digestive and Kidney Diseases, Bethesda, Md., USA. The content is solely the responsibility of the authors and does not necessarily represent the official views of the National Center for Research Resources or the National Institutes of Health.

This work was previously presented in poster format at the American Society of Nephrology Kidney Week, in Denver, Colo., USA in November 2010.

\section{Disclosure Statement}

None of the authors have any financial disclosures or conflicts of interest to report.

\section{References}

-1 Plantinga LC, Boulware LE, Coresh J, Stevens LA, Miller ER 3rd, Saran R, Messer KL, Levey AS, Powe NR: Patient awareness of chronic kidney disease: trends and predictors. Arch Intern Med 2008;168:2268-2275.

$\checkmark 2 \mathrm{~K} / \mathrm{DOQI}$ clinical practice guidelines for chronic kidney disease: evaluation, classification, and stratification. Am J Kidney Dis 2002;39:S1-S266.

- 3 Hostetter TH, Lising M: National kidney disease education program. J Am Soc Nephrol 2003; 14:S114-S116.

-4 Ravera M, Noberasco G, Weiss U, Re M, Gallina AM, Filippi A, Cannavo R, Ravera G, Cricelli C, Deferrari G: CKD awareness and blood pressure control in the primary care hypertensive population. Am J Kidney Dis 2011;57:71-77.

- 5 Allen AS, Forman JP, Orav EJ, Bates DW, Denker BM, Sequist TD: Primary care management of chronic kidney disease. J Gen Intern Med 2011;26:386-392.

-6 Peralta CA, Hicks LS, Chertow GM, Ayanian JZ, VittinghoffE, Lin F, Shlipak MG: Control of hypertension in adults with chronic kidney disease in the United States. Hypertension 2005;45:1119-1124.

-7 Sarafidis PA, Li S, Chen SC, Collins AJ, Brown WW, Klag MJ, Bakris GL: Hypertension awareness, treatment, and control in chronic kidney disease. Am J Med 2008;121: 332-340.

8 National Center for Health Statistics: Plan and operation of the Third National Health and Nutrition Examination Survey, 1988-
1994. Series 1: programs and collection procedures. Vital Health Stat 1 1994;32:1-407.

9 Centers for Disease Control and Prevention. National Center for Health Statistics. National Health and Nutrition Examination Survey Questionnaire, 1999-2000, 20012002, 2003-2004, 2005-2006, 2007-2008, 2009-2010. Hyattsville, MD, U.S. Department of Health and Human Services, Centers for Disease Control and Prevention. http://www.cdc.gov/nchs/nhanes/nhanes_ questionnaires.htm. Accessed August 2011.

10 Appel LJ, Wright JT Jr, Greene T, Agodoa LY Astor BC, Bakris GL, Cleveland $\mathrm{WH}$, Charleston J, Contreras G, Faulkner ML, Gabbai FB, Gassman JJ, Hebert LA, Jamerson KA, Kopple JD, Kusek JW, Lash JP, Lea JP, Lewis JB, Lipkowitz MS, Massry SG, Miller ER, Norris K, Phillips RA, Pogue VA, Randall OS, Rostand SG, Smogorzewski MJ, Toto RD, Wang X: Intensive blood-pressure control in hypertensive chronic kidney disease. N Engl J Med 2010;363:918-929.

11 Skyler JS, Bergenstal R, Bonow RO, Buse J, Deedwania P, Gale EA, Howard BV, Kirkman MS, Kosiborod M, Reaven P, Sherwin RS: Intensive glycemic control and the prevention of cardiovascular events: implications of the ACCORD, ADVANCE, and VA diabetes trials: a position statement of the American Diabetes Association and a scientific statement of the American College of Cardiology Foundation and the American Heart Association. Circulation 2009; 119: 351-357.
12 Levey AS, Coresh J, Greene T, Stevens LA, Zhang YL, Hendriksen S, Kusek JW, Van Lente F: Using standardized serum creatinine values in the modification of diet in renal disease study equation for estimating glomerular filtration rate. Ann Intern Med 2006; 145:247-254

13 Selvin E, Manzi J, Stevens LA, Van Lente F, Lacher DA, Levey AS, Coresh J: Calibration of serum creatinine in the National Health and Nutrition Examination Surveys (NHANES) 1988-1994, 1999-2004. Am J Kidney Dis 2007;50:918-926.

14 Analytic and reporting guidelines: The National Health and Nutrition Examination Survey (NHANES). Available at: http:// www.Cdc.Gov/nchs/nhanes/nhanes 2003-2004/analytical_guidelines.htm; in U.S. Department of Health and Human Services CfDCaP (ed). Hyattsville, MD, 2006.

15 Levey AS, Stevens LA, Schmid CH, Zhang YL, Castro AF 3rd, Feldman HI, Kusek JW, Eggers P, Van Lente F, Greene T, Coresh J: A new equation to estimate glomerular filtration rate. Ann Intern Med 2009;150:604612.

16 Whaley-Connell A, Sowers JR, McCullough PA, Roberts T, McFarlane SI, Chen SC, Li S, Wang C, Collins AJ, Bakris GL: Diabetes mellitus and CKD awareness: the Kidney Early Evaluation Program (KEEP) and National Health and Nutrition Examination Survey (NHANES). Am J Kidney Dis 2009; 53:S11-S21. 
-17 Flessner MF, Wyatt SB, Akylbekova EL, Coady S, Fulop T, Lee F, Taylor HA, Crook E: Prevalence and awareness of CKD among African Americans: the Jackson Heart Study. Am J Kidney Dis 2009;53:238-247.

- 18 Bodenheimer T, Lorig K, Holman H, Grumbach K: Patient self-management of chronic disease in primary care. JAMA 2002;288: 2469-2475.

19 Lorig KR, Sobel DS, Ritter PL, Laurent D, Hobbs M: Effect of a self-management program on patients with chronic disease. Eff Clin Pract 2001;4:256-262.

-20 Lorig K, Ritter PL, Villa F, Piette JD: Spanish diabetes self-management with and without automated telephone reinforcement: two randomized trials. Diabetes Care 2008;31: 408-414.
21 Hunt SA, Abraham WT, Chin MH, Feldman AM, Francis GS, Ganiats TG, Jessup M, Konstam MA, Mancini DM, Michl K, Oates JA, Rahko PS, Silver MA, Stevenson LW, Yancy CW: 2009 Focused update incorporated into the ACC/AHA 2005 Guidelines for the Diagnosis and Management of Heart Failure in Adults A Report of the American College of Cardiology Foundation/American Heart Association Task Force on Practice Guidelines Developed in Collaboration With the International Society for Heart and Lung Transplantation. J Am Coll Cardiol 2009; 53:e1-e90.

22 Roumie CL, Elasy TA, Greevy R, Griffin MR, Liu X, Stone WJ, Wallston KA, Dittus RS, Alvarez V, Cobb J, Speroff T: Improving blood pressure control through provider education, provider alerts, and patient education: a cluster randomized trial. Ann Intern Med 2006;145:165-175.
23 Devins GM, Mendelssohn DC, Barre PE, Binik YM: Predialysis psychoeducational intervention and coping styles influence time to dialysis in chronic kidney disease. Am J Kidney Dis 2003;42:693-703.

24 Devins GM, Mendelssohn DC, Barre PE, Taub K, Binik YM: Predialysis psychoeducational intervention extends survival in CKD: a 20-year follow-up. Am J Kidney Dis 2005; 46:1088-1098.

25 Wright JA, Wallston KA, Elasy TA, Ikizler TA, Cavanaugh KL: Development and results of a kidney disease knowledge survey given to patients with CKD. Am J Kidney Dis 2011;57:387-395. 